\title{
Glycol Chitosan-Based Nanogel as a Potential Targetable Carrier for siRNA
}

\author{
Paula Pereira, Daniela Morgado, Agnès Crepet, Laurent David, \\ Francisco M. Gama*
}

A self-assembled glycol chitosan nanogel (GC) is synthesized by chemically grafting hydrophobic chains onto a polysaccharide, which is comprehensively characterized. The obtained macromolecular micelle is decorated with folate-conjugated poly(ethylene glycol) (PEG) (GCFA). An average size distribution of 250 and $200 \mathrm{~nm}$ is observed, respectively for the GC and GCFA nanogels. Differential cell localization is observed on incubating the materials with HeLa cells. Whereas the GC nanogel is detected on the cell surface, GCFA is localized in the cytoplasm. The cell viability is not compromised by the nanogels. Interestingly, GC nanogel is poorly internalized by bone marrow derived macrophages (BMDMs), and GCFA is not phagocytosed. Given its ability to complex siRNA, the targetable GC nanogel can be a promising vehicle for

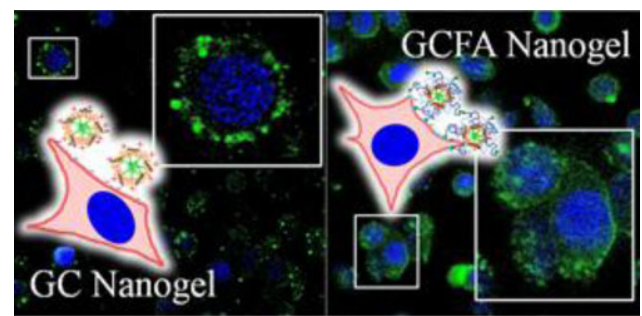
siRNA delivery.

\section{Introduction}

Gene therapy is an emerging field in medical and pharmaceutical sciences. However, naked therapeutic genes are rapidly degraded by nucleases, showing poor and non-specific cellular uptake and low transfection efficiency. ${ }^{[1]}$ Therefore the development of a safe and efficient gene carrier is primordial for the success of gene therapy. Systems based on chitosan macromolecular micelles, commonly called nanogels, are now extensively used in drug delivery; they form stable complexes with nucleic acids, protect them from

P. Pereira, F. M. Gama

Institute for Biotechnology and Bioengineering (IBB), Centre for Biological Engineering, Campus de Gualtar University of Minho, Braga, Portugal

E-mail: fmgama@deb.uminho.pt

D. Morgado, A. Crepet, L. David

Université de Lyon, Université Claude Bernard Lyon 1, Ingéniérie des Matériaux Polymères, (IMP@Lyon1), CNRS UMR 5223, 15 Bd

Latarjet 69622 Villeurbanne, Cedex, France nuclease degradation, interact readily with cellular membrane, and show pH buffering capacity, which is critical for endosomal escape and subsequent gene silencing efficiency, although less efficiently than poly (ethylene imine). ${ }^{[2]}$

Chitosan is obtained from chitin - a main component of the exoskeleton of insects, crustaceous and cell walls of fungi-by deacetylation. This linear polysaccharide is composed of glucosamine and $N$-acetylglucosamine units linked through glycosidic bonds. ${ }^{[3]}$ It gathers a number of desirable characteristics such as: cationic charge, biodegradability, biocompatibility, low toxicity, muco-adhesiveness, and reactive sites for chemical modifications. ${ }^{[2,4]}$ However, its poor solubility at physiological and basic $\mathrm{pH}$ ( $\mathrm{p} K_{\mathrm{a}}$ values range from 6.2 to 7 ), has limited its effective utilization. ${ }^{[5]}$ Among watersoluble chitosan derivatives chitosan nanogel (GC) has emerged as novel gene carrier due to its solubility at physiological $\mathrm{pH}$ provided by ethylene oxide units, besides its proved biocompatibility in vivo. ${ }^{[6,7]}$ Its positive charge under slightly acidic conditions allows the electrostatic interaction between GC and negatively charged siRNA. 
The siRNA loading depends among other parameters on the N/P ratio, defined as the molar ratio of chitosan amino groups to nucleic acid phosphate groups. Higher N/P ratios have been required to complex siRNA efficiently and achieve the greatest level of silencing. ${ }^{[4]}$ Under neutral or alkaline conditions the binding is stabilized essentially by hydrogen bonding and hydrophobic interactions. ${ }^{[8]}$ Successful transfection efficiency is also related to a specific cellular uptake. In this study, folate was selected as model targeting molecule because folate receptors are overexpressed in a wide range of tumors and rarely found in normal cells. ${ }^{[9]}$ Folate was conjugated to GC using a PEG linker. Since Chan et al. ${ }^{[10]}$ verified that folate grafting slightly decreases the solubility, we added an extra amount of PEG to overcome this issue. PEGlyation - in addition to improving the solubility - also reduces the opsonin adsorption and subsequent scavenging by the mononuclear phagocyte system, enhancing the longevity of a nanogel in blood. ${ }^{[11]}$

The aim of present study was to develop GC based nanogel through chemical grafting of hydrophobic chains on the hydrophilic backbone, resulting in an amphiphilic polymer capable of self-assembling in aqueous environment. The targeting ability was assessed using folate as a ligand. The ability of GC nanogel to complex siRNA was evaluated to explore their potential as an siRNA delivery system. Cell viability and the response of macrophages to nanogel were also investigated. The results showed that GC nanogel is a promising carrier for targeted gene delivery.

\section{Experimental Section}

\subsection{Materials}

Culture medium reagents were purchased from Biochrom. GC (G7753), mercapto hexadecanoic acid (MHDA), folate, $N$-hydroxysulfosuccinimide (NHS), 1-ethyl-3-[3-dimethylaminopropyl]carbodiimide hydrochloride (EDC), O-methyl-O'-succinylpolyethyene glycol 2000 (PEG2000), O-(2-aminoethyl)-O'-(2-carboxyethyl)polyethylene glycol 3000 hydrochloride (PEG3000) were acquired from Sigma-Aldrich. 5/6-Carboxyfluorescein succinimidyl ester was purchased from Thermo Scientific.

\subsection{GC Analysis}

\subsection{1. ${ }^{1} \mathrm{H}$ Nuclear Magnetic Resonance ( ${ }^{1} \mathrm{H}$ NMR) Spectroscopy Analysis}

The ${ }^{1} \mathrm{H}$ NMR spectra were obtained using a Varian Unity Plus 300 spectrometer operating at $299.94 \mathrm{MHz}$ and $70^{\circ} \mathrm{C}$. The GC solution sample was prepared at $10 \mathrm{mg} \mathrm{mL}^{-1}$ in $2 \% \mathrm{DCl} / \mathrm{D}_{2} \mathrm{O} .0 .05 \mathrm{wt} \% 3-$ (trimethylsilyl)propionic-2,2,3,3-d4 acid (TSP) was used as a quantification reference for all chemical shifts.

\subsubsection{Refractive-Index Increment (dn/dc)}

$\mathrm{d} n / \mathrm{d} c$ was evaluated using a differential refractometer operating at $\lambda=658 \mathrm{~nm}$ (Optilab rEX). Six solutions (a parent solution and five dilutions) were analyzed to determine each value of $\mathrm{d} n / \mathrm{d} c$.

\subsubsection{Gel-Permeation Chromatography}

Size-exclusion chromatography (SEC) was coupled online with a multiangle laser light scattering (MALLS) detector. SEC was performed by means of an IsoChrom LC pump (Spectra Physics) connected to TSK gel 2500PW and TSK gel 6000PW columns. An Optilab rEX differential refractometer and a multiangle laser-light scattering detector, operating at $690 \mathrm{~nm}$ (Wyatt Dawn EOS) and 18 angles, were connected online. A $0.15 \mathrm{M}$ ammonium acetate $/ 0.2 \mathrm{M}$ acetic acid buffer ( $\mathrm{pH}$ 4.5) was used as the eluent. The flow rate was $0.5 \mathrm{~mL} \mathrm{~min}^{-1}$. The polymer solutions were prepared by dissolving $1 \mathrm{mg}$ of polymer in $1 \mathrm{~mL}$ of buffer solution, then filtered on a $0.45 \mu \mathrm{m}$ pore size membrane (Millipore) before the injection of $50 \mu \mathrm{L}$ of solution.

\subsection{Self-Assembled Nanogel Synthesis}

\subsubsection{Preparation of GC Nanogel}

GC nanogel was prepared by chemical conjugation of MHDA to GC, through carbodiimide chemistry, as depicted in Scheme 1A. ${ }^{[12,13]}$ In detail, GC (200 mg) was dissolved in $24 \mathrm{~mL}$ of distilled water at $50^{\circ} \mathrm{C}$ for $2 \mathrm{~h}$, under magnetic stirring. Then the GC solution was diluted in methanol 1:3 v/v (water/methanol). After homogenization, MHDA was added according to the desirable degree of substitution (DS) and left dissolving for $3 \mathrm{~h}$. EDC and NHS were then mixed (both in 1.5-fold molar excess with regard to MHDA) to activate the MHDA. The reaction was performed for $24 \mathrm{~h}$ at $50^{\circ} \mathrm{C}$ under magnetic stirring. The reaction product was extensively dialysed (molecular weight cutoff $(M W C O)=10-12 \mathrm{kDa}$ ) against distilled water, followed by freezedrying. The lyophilized GC nanogel, a blank fluffy product, was stored at room temperature.

\subsubsection{Functionalization of GC Nanogel with Folate (GCFA Nanogel)}

The functionalization of nanogel with folate occurred in two steps. In the first step, folate was conjugated to PEG3000 (FA-PEG3000), as described by Zheng et al. ${ }^{[14]}$; then, in the second step, FA-PEG3000, PEG2000, and MHDA were grafted on the GC polymer. In brief, folate was activated by reacting with EDC and NHS (using 10 and 1.2-fold molar excesses, respectively) in anhydrous DMSO, for $3 \mathrm{~h}$. Then, 2-mercaptoethanol (tenfold molar excess to EDC) was added to quench the unreacted EDC. The reactive folate solution was joined by adding it dropwise to PEG3000 dissolved in anhydrous DMSO, under stirring. The reaction was conducted for $18 \mathrm{~h}$, at room temperature, in the dark. The resulting mixture was dialysed $(\mathrm{MWCO}=1 \mathrm{kDa})$ first against DMSO, to remove unbounded folate and then with distilled water. The dialyzed product was freezedried. The second step consisted of the same reaction as described 
A)
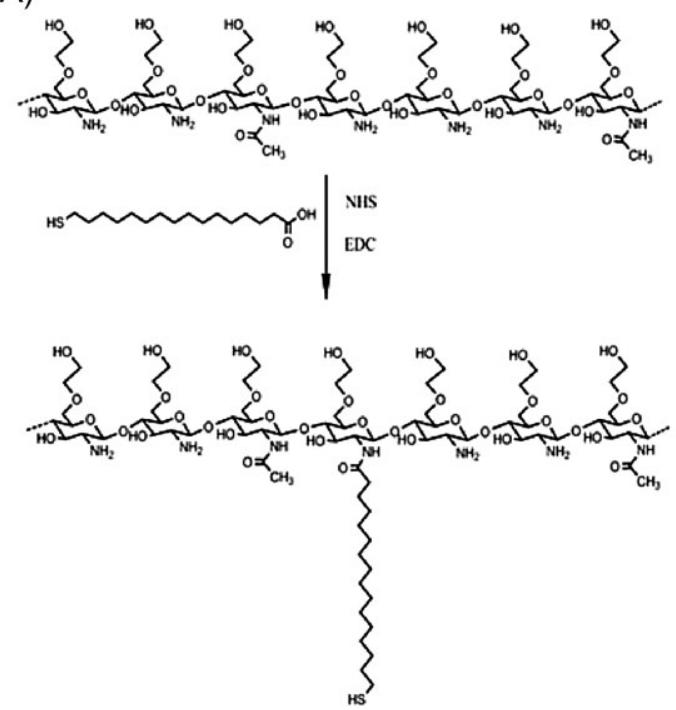

B)
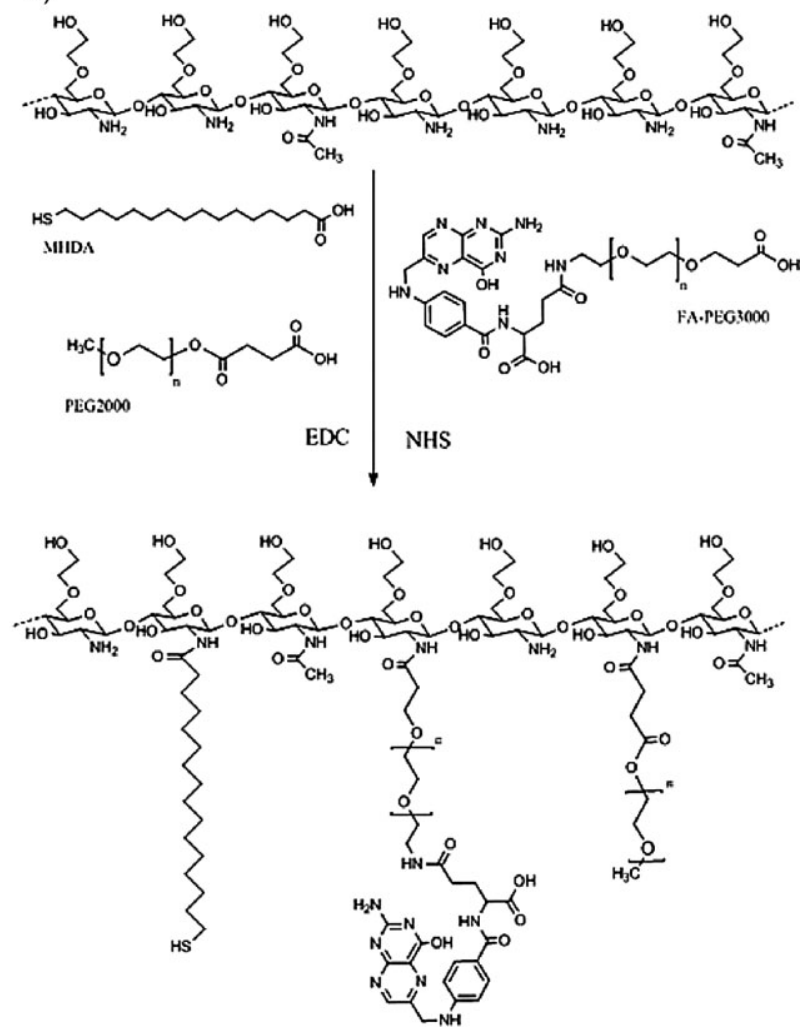

Scheme 1. Representation of A) GC and B) GCFA nanogels synthesis.

above for the GC nanogel synthesis; however, in this case, in addition to MHDA, FA-PEG3000 and PEG2000 were also added to the reaction mixture, as shown in Scheme 1B. The lyophilized GCFA nanogel had a yellowish tonality; it was stored at room temperature, protected from light.

\subsubsection{Nanogel Self-Assembly}

The lyophilized samples were dispersed in distilled water under magnetic stirring at $50{ }^{\circ} \mathrm{C}$. After $48 \mathrm{~h}$, the nanogel solution was filtered using a membrane with a pore size of $0.45 \mu \mathrm{m}$ and stored at $4^{\circ} \mathrm{C}$.

\subsection{Nanogel Characterization}

\subsection{1. ${ }^{1} \mathrm{H}$ NMR Spectroscopy Analysis}

The MHDA substitution degree was quantified by preparing a nanogel dispersion with a concentration of $7 \mathrm{mg} \mathrm{mL}^{-1}$ in $2 \% \mathrm{v} / \mathrm{v}$ $\mathrm{DCl} / \mathrm{D}_{2} \mathrm{O}$ followed by the acquisition of ${ }^{1} \mathrm{H}$ NMR spectra on a Varian Unity Plus 300 spectrometer operating at $299.94 \mathrm{MHz}$ at $70{ }^{\circ} \mathrm{C}$.

\subsubsection{Dynamic Light Scattering (DLS)}

The size distribution, mean hydrodynamic diameter, and surface charge of the nanogels were evaluated using a Malvern Zetasizer
NANO ZS (Malvern Instruments Limited, UK). The nanogel dispersions ( $1 \mathrm{mg} \mathrm{mL}^{-1}$ in distilled water, prepared as described above) were analyzed at $25^{\circ} \mathrm{C}$ in a polystyrene cell using a detector angle of $173^{\circ}$.

\subsubsection{Cryo-Field-Emission Scanning Electron Microscopy (Cryo-FESEM)}

The GC nanogel $\left(1 \mathrm{mg} \mathrm{mL}^{-1}\right.$ in distilled water) was frozen at $-200{ }^{\circ} \mathrm{C}$ with liquid nitrogen and transferred to the cryo stage (Gatan, Alto 2500, UK) of an electron microscope (SEM/EDS: FESEM JEOL JSM6301F/Oxford Inca Energy 350). Each sample was fractured with a knife, and sublimated for $10 \mathrm{~min}$ at $-95^{\circ} \mathrm{C}$ to remove an ice layer, allowing the nanogels to be exposed. At $-140^{\circ} \mathrm{C}$, the samples were sputter-coated with gold and palladium using an accelerating voltage of $10 \mathrm{kV}$. The samples observation was done at $-140{ }^{\circ} \mathrm{C}$ and $15 \mathrm{kV}$.

\subsubsection{Fluorescence Spectroscopy}

The critical aggregation concentration (CAC) of the GC and GCFA nanogels were determined measuring the fluorescence intensity of a hydrophobic probe Nile Red (NR) loaded onto the core of the nanogel. Lyophilized nanogel was dispersed in water at $1 \mathrm{mg} \mathrm{mL}^{-1}$, as above-mentioned. Then, nanogel suspension was diluted to a range of concentrations from 1 to $0.001 \mathrm{mg} \mathrm{mL}^{-1}$ in $1 \mathrm{~mL}$ of final volume. Then, $5 \mu \mathrm{L}$ of an NR solution with a concentration of

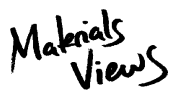

www.MaterialsViews.com 
$4 \times 10^{-5} \mathrm{M}$ in ethanol was added to each tube, yielding an NR final concentration of $2 \times 10^{-7} \mathrm{M}$ and $0.5 \%$ of ethanol. The nanogel solutions containing NR were left overnight in a turning wheel to keep the solution agitated, at room temperature. The solutions were then analyzed using a Spex Fluorolog 3 spectrofluorimeter, with excitatoin at $550 \mathrm{~nm}$ and recording the emission in the range from 560 to $760 \mathrm{~nm}$.

\subsection{Cell Culture}

\subsubsection{HeLa Cell Line}

HeLa cells (HeLa T-REx, from Invitrogen) were maintained at $37^{\circ} \mathrm{C}$ in a humidified air containing $5 \% \mathrm{CO}_{2}$ in RPMI-1640 supplemented with $10 \%$ heat-inactivated fetal bovine serum (FBS), $100 \mathrm{IU} \mathrm{mL}^{-1}$ penicillin and $0.1 \mathrm{mg} \mathrm{mL}^{-1}$ streptomycin.

\subsubsection{Mouse Leukemic Monocyte Macrophage (RAW) Cell} Line

The RAW cell line RAW 264.7 (ATCC TIB-71) was maintained in Dulbecco's modified Eagle medium (DMEM) supplemented with $10 \% \mathrm{FBS}$ and $100 \mathrm{IU} \mathrm{mL}^{-1}$ penicillin and $0.1 \mathrm{mg} \mathrm{mL}^{-1}$ streptomycin. The cells were incubated at $37^{\circ} \mathrm{C}$ in a humidified air containing $5 \% \mathrm{CO}_{2}$.

\subsubsection{Murine Bone-Marrow-Derived Macrophages} (BMDM)

Procedures involving mice were performed according to the European Convention for the Protection of Vertebrate Animals used for Experimental and Other Scientific Purposes (ETS 123) and 86/609/EEC Directive and Portuguese rules (DL 129/92). Macrophages were collected from femoral and tibial mouse bone marrow. Mouse long bones were extracted from the mouse under aseptic conditions and flushed with RPMI-1640. The resulting cell suspension was centrifuged at $500 \mathrm{~g}$ during $10 \mathrm{~min}$. The cell pellet was resuspended in RPMI-1640 supplemented with $10 \mathrm{mM}$ HEPES, 10\% heat-inactivated FBS, $60 \mu \mathrm{g} \mathrm{mL}^{-1}$ penicillin/ streptavidin, $0.005 \mathrm{mM} \beta$-mercaptoethanol (RPMI complete medium), and 10\% L929 cell conditioned medium (LCCM). To remove adherent bone marrow cells, the cell suspension was incubated overnight at $37^{\circ} \mathrm{C}$ and $5 \% \mathrm{CO}_{2}$ atmosphere in a Petri dish. The nonadherent cells were collected, centrifuged at $500 \mathrm{~g}$ (10 min) and seeded in 24 -well plates at $5 \times 10^{5}$ cells per well in RPMI complete medium containing $10 \%$ of LCCM and incubated at $37^{\circ} \mathrm{C}$ in a $5 \% \mathrm{CO}_{2}$ atmosphere. Four days after seeding $10 \%$ of LCCM was re-added to the cultures. The culture medium was replaced with fresh RPMI complete medium containing 10\% LCCM on Day 7. After $10 \mathrm{~d}$ in culture, cells were completely differentiated into macrophages. ${ }^{[15,16]}$

\subsection{In Vitro Cell Cytotoxicity Studies}

Cells were seeded in 96-well plates at a density of 2500 per well for HeLa and 5000 for RAW cell lines, and left adhering in $0.2 \mathrm{~mL}$ of culture medium overnight. The medium was replaced by nanogel dispersions in culture medium containing $25 \%$ of water $\mathrm{v} / \mathrm{v}$. After 24,48 , and $72 \mathrm{~h}$ the cellular viability was determined using the MTT (3-(4,5-dimethylthiazol-2-yl)-2,5-diphenyl tetrazolium bromide $)^{[17]}$ quantitative colorimetric assay. The tetrazolium salt is reduced by metabolically active cells using mitochondrial succinate dehydrogenase enzymes. The resulting dark blue formazan crystals could be solubilized in dimethyl sulfoxide and quantified spectrophotometrically at $570 \mathrm{~nm}$, subtracting the background optical density (690 $\mathrm{nm})$. The test was performed in triplicate.

\subsection{Cellular Uptake}

\subsubsection{Preparation of NHS-Fluorescein Nanogel}

The production of GC and GCFA nanogels labeled with NHSfluorescein was achieved by grafting the fluorophore agent through an amide linkage, as described ahead. The NHSfluorescein was dissolved in DMSO, at a concentration of $1 \%$. The molar ratio of NHS-fluorescein carboxylic groups to the GC and GCFA nanogels free amine groups was 0.25 . The dye was added to a stirred nanogel suspension at a concentration of $1 \mathrm{mg} \mathrm{mL}^{-1}$ in PBS. The reaction was allowed to occur overnight at room temperature, in the dark. The reaction mixture was thoroughly dialysed (MW cutoff $10-12 \mathrm{kDa}$ ) against distilled water to remove free NHS-fluorescein. As to verifying the absence of free dye, the final solution of nanogel-fluorescein was purified by centrifugation through a $10 \mathrm{kDa}$ MWCO filter.

\subsubsection{Confocal Laser Scanning Microscopy}

HeLa cells and BMDM were seeded at a density of $5 \times 10^{-5}$ cells per well in a 24-well plate (with a coverslip in each well), and left adhering overnight. The cells were incubated with $0.2 \mathrm{mg} \mathrm{mL}^{-1}$ of each nanogel-fluorescein suspension in culture medium containing $25 \%$ of water $\mathrm{v} / \mathrm{v}$. After $6 \mathrm{~h}$, the coverslips were washed twice with PBS at room temperature and the cells were fixed with paraformaldehyde $2 \%$ for $25 \mathrm{~min}$. After washing the cells twice with PBS twice, 4',6-diamidino-2-phenylindole (DAPI) (120 ng $\mathrm{mL}^{-1}$ ) was used to stain the nucleus for $3 \mathrm{~min}$ at room temperature. After washing, the preparations were observed in a confocal laser scanning microscope Leica SP2 AOBS SE (Leica Mycrosystems, Germany).

\section{8. siRNA-Nanogel Interaction}

The siRNA binding ability of the nanogel was tested by gel retardation assay. Suspensions of the nanogel in buffer solution at $\mathrm{pH} 4.5$ were mixed with siRNA $(1 \mu \mathrm{g})$ under three different molar ratios of amine to phosphate groups, and gently vortexed. The formulations nanogel/siRNA were incubated for $30 \mathrm{~min}$ at room temperature prior to loading into a $4 \%$ agarose gel electrophoresis to allow the formation of the nanogel/siRNA complexes. The electrophoresis was carried out at $100 \mathrm{~V}$ for $30 \mathrm{~min}$ in Tris-acetate-EDTA buffer $(40 \mathrm{mM}$ Tris-HCl, 1\% v/v acetic acid, $1 \mathrm{mM}$ EDTA). SYBR safe was used to visualize siRNA using a UV transilluminator at $365 \mathrm{~nm}$. 


\subsection{Statistical Analysis}

Data were expressed as mean \pm stand. deviation. All the statistics to cell viability results were performed applying two-way analysis of variance (ANOVA) tests through Prism software (GraphPad software version 5.00, USA). Differences were considered significant when $p<0.05$.

\section{Results and Discussion}

\subsection{GC Characterization}

The GC used for nanogel synthesis was purchased from Sigma-Aldrich. A comprehensive characterization of this material is not available in the product data sheet and the characterization found in the literature is not consistent. ${ }^{[18-}$ ${ }^{22}$ Therefore, the degree of deacetylation and the molecular weights of the polymer were analyzed by ${ }^{1} \mathrm{H} N M R$ spectroscopy and SEC.

Figure 1 shows the ${ }^{1} \mathrm{H}$ NMR spectrum of GC dissolved in $2 \% \mathrm{v} / \mathrm{v} \mathrm{DCl} / \mathrm{D}_{2} \mathrm{O}$, obtained at $70{ }^{\circ} \mathrm{C}$. The characterization of GC by ${ }^{1} \mathrm{H}$ NMR spectroscopy has been extensively used, since it allows the straightforward assignment of the GC proton peaks ${ }^{[22]}$ and thereby the determination of the degree of deacetylation. ${ }^{[23]}$ The ${ }^{1} \mathrm{H}$ NMR spectroscopy measurements at $70^{\circ} \mathrm{C}$ cause the shift of the solvent proton peak from $4.8 \mathrm{ppm}$ to 4.3 , allowing the $\mathrm{H}-1$ peak to become visible. A GC degree of deacetylation of $\approx 88 \%$ was calculated according to the approach described by Lavertu et al., ${ }^{[23]}$ using the integral intensity of the proton $\mathrm{H} 1$ of deacetylated monomer (H1-D) and the three protons of methyl group $\left(-\mathrm{CH}_{3}\right)$. The degree of deacetylation was also determined according to Hirai et al. ${ }^{[24]}$ equation and a similar value was achieved.

The SEC-MALLS GC mass determination, namely the number, weight and Z-average molecular weight $\left(\bar{M}_{\mathrm{n}}, \bar{M}_{\mathrm{w}}\right.$,
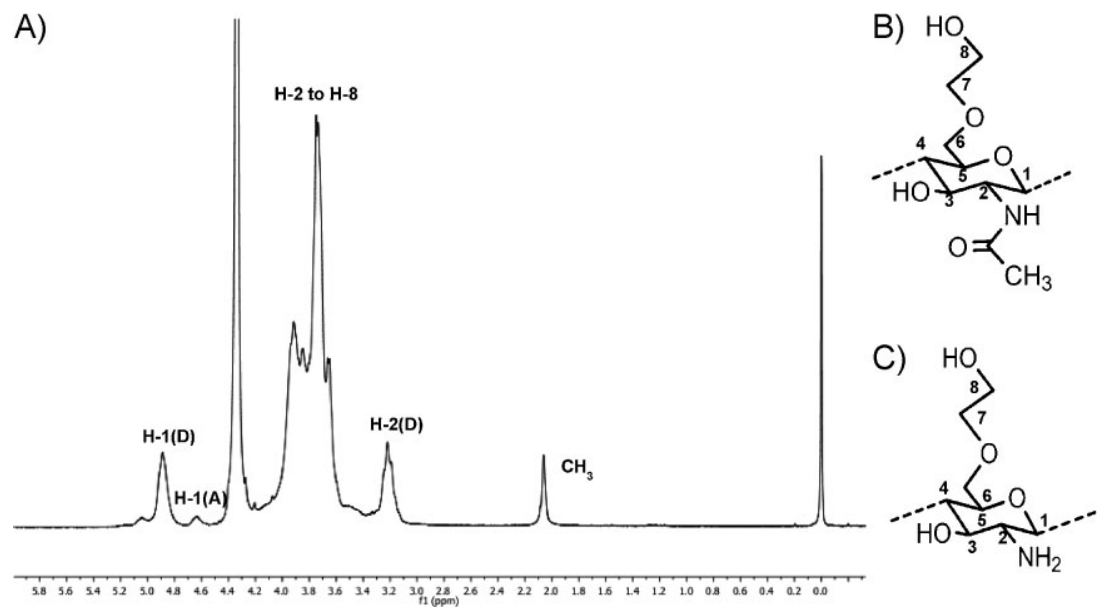

Figure 1. Three-hundred megahertz ${ }^{1} \mathrm{H}$ NMR spectrum of GC in $2 \% \mathrm{v} / \mathrm{v} \mathrm{DCl} / \mathrm{D}_{2} \mathrm{O}$ at $70^{\circ} \mathrm{C}$ (A) and schematic representation of GC monomer acetylated (B) and deacetylated (C).
Table 1. SEC-MALLS characterization of GC using a value of $\mathrm{d} n$ / $\mathrm{dc}=0.153 \mathrm{mLg}^{-1}$.

\begin{tabular}{lccc}
$\begin{array}{l}\bar{M}_{\mathrm{n}} \\
{\left[\mathrm{g} \mathrm{mol}^{-1}\right]}\end{array}$ & $\overline{\boldsymbol{M}}_{\mathrm{w}}$ & $\overline{\boldsymbol{M}}_{\mathrm{z}}$ & \\
{$\left[\mathrm{g} \mathrm{mol}^{-1}\right]$} & {$\left[\mathrm{g} \mathrm{mol}^{-1}\right]$} & $\overline{\boldsymbol{M}}_{\mathrm{w}} / \overline{\boldsymbol{M}}_{\mathrm{n}}$ \\
\hline
\end{tabular}

$67000 \pm 5 \% \quad 100000 \pm 3 \% \quad 167000 \pm 13 \% \quad 1.509 \pm 6 \%$

and $\bar{M}_{\mathrm{z}}$, respectively) and polydispersity index $\left(\bar{M}_{\mathrm{w}} / \bar{M}_{\mathrm{n}}\right)$ are described in Table 1.

The values of $\bar{M}_{\mathrm{n}}(67 \mathrm{kDa})$ and $\bar{M}_{\mathrm{w}}(100 \mathrm{kDa})$ obtained are not in agreement with those reported by Knight et al. ${ }^{[22]} 178$ and $237 \mathrm{kDa}$, respectively, although GC from Sigma was used also in that case. Also using the same source, Park et al. ${ }^{[21]}$ reported a $\bar{M}_{\mathrm{w}}$ of $250 \mathrm{kDa}$. Also regarding the GC degree of acetylation some inconsistency is noted comparing the values obtained in this work with those reported in the literature: Dufes et al. ${ }^{[19]}$ obtained a value of $33 \%$ and Park et al. ${ }^{[21]}$ $17.3 \%$. It is not clear whether the different samples described in the literature correspond to different batches of glycol chitosan or whether the different properties reported arise from technical issues. Nevertheless, the properties of GC used for the development of biomedical materials must be well-characterized in order to make possible a proper comparison of data obtained in different labs.

\subsection{Synthesis and Physicochemical Characterization of Nanogels}

The covalent attachment of hydrophobic chains on the hydrophilic GC backbone results in the generation of amphiphilic material, which self-assembles in water. The decoration of the nanogel with FAPEG3000 and PEG2000 was also mediated by a crosslinking reaction. The presence of MHDA, PEG, and folate on the polysaccharide were confirmed by ${ }^{1} \mathrm{H}$ NMR spectroscopy. The MHDA DS was calculated from the following equation:

$$
\mathrm{DS}_{\mathrm{MHDA}}=\frac{12 a}{26 b} \times 100
$$

where $a$ represents the integral of MHDA $-\mathrm{CH}_{2}-$ protons signal detected between 1.2 and $1.6 \mathrm{ppm}$ (which does not include the $-\mathrm{CH}_{2}-$ protons signals next to the carbonyl and thiol groups) and $b$ the integral of GC proton peaks observed from 3 to 4.2 ppm, (Figure 2A). The DS obtained

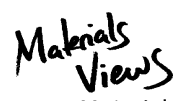

www.MaterialsViews.com 
A)

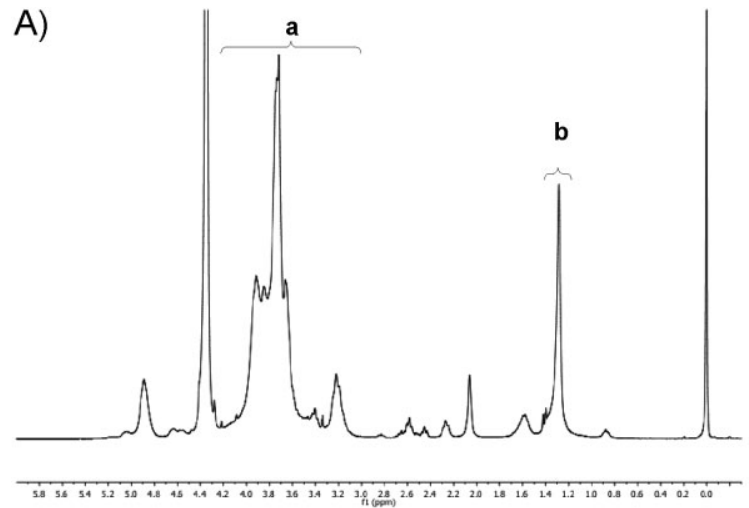

B)

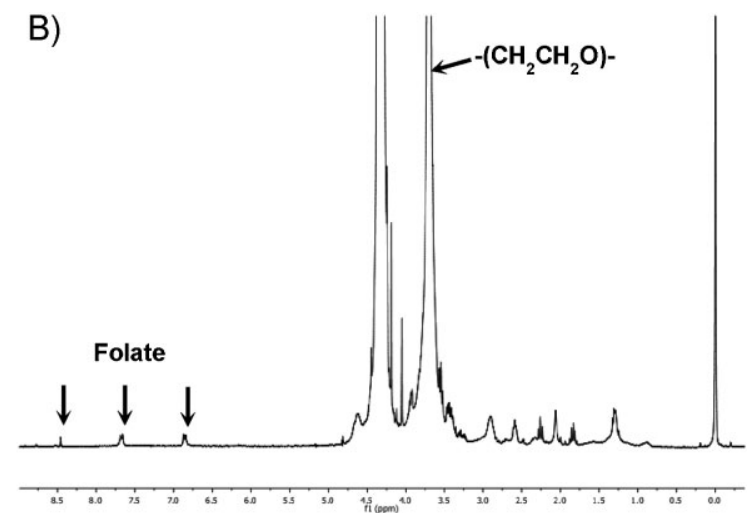

Figure 2. ${ }^{1} \mathrm{H}$ NMR spectra of A) GC nanogel and B) GCFA in $2 \% \mathrm{v} / \mathrm{v} \mathrm{DCl} / \mathrm{D}_{2} \mathrm{O}$ at $70^{\circ} \mathrm{C}$.

was about $9 \%$, that is, 9 out of 100 sugar residues are substituted with the alkane chain. Given the theoretical DS, $15 \%$, the reaction efficiency is about $60 \%$. The yield reaction was reproducible for all batches.

The successful conjugation of FA-PEG3000 and PEG2000 on GC was confirmed by the presence of characteristic peaks between 6 and 9 ppm assigned to aromatic protons of folic acid and at $\approx 3.7 \mathrm{ppm}\left(-\mathrm{CH}_{2} \mathrm{CH}_{2} \mathrm{O}-\right)$ for PEG protons (Figure 2B). ${ }^{[14]}$ Nonetheless, it has not been possible to determine the corresponding DS due to overlapping of the proton signal derived from PEG and sugar residues. Since these molecules are grafted through a similar reaction used for MHDA, it may be speculated that the reaction yield might have been similar. Based on this assumption, the FA-PEG3000 and PEG2000 DS would correspond to 6 and 12\%, respectively. PEG was used to improve the folate water-solubility, also performing as a spacer and enabling an efficient binding to the folate receptor. ${ }^{[14,25]}$

Self-assembled nanogels give rise to a unimodal particle size distributions, between 100 and $400 \mathrm{~nm}$ for the GC nanogel (Figure 3A), with an average size of $250 \mathrm{~nm}$, and between 60 and $500 \mathrm{~nm}$ for GCFA (Figure 3C) with $200 \mathrm{~nm}$ as mean diameter. The functionalized nanogel population was slightly more polydisperse than GC nanogel, with polydispersity indexes of 0.4 and 0.3 , respectively. The surface charge of the nanogels in aqueous solution was positive (potential zeta of about 25-30 mV) due to presence of protonated amine groups. As expected, the GCFA nanogel $25^{\circ} \mathrm{C}$. surface charge was less positive, because fewer free amine groups are available. The nanogel morphology under cryoFESEM was spherical as shown in Figure 3B, and the size distribution observed confirm the results obtained by dynamic light scattering (DLS). Cryo-FESEM allows the observation of the nanogel close to its natural liquid state, preserving the three dimensional structure ${ }^{[26]}$ The stability of the nanogels in aqueous solution was studied over time by DLS. As observed in Figure 3D, both nanogels are stable for at least four months, which represents a high colloidal stability.
A)

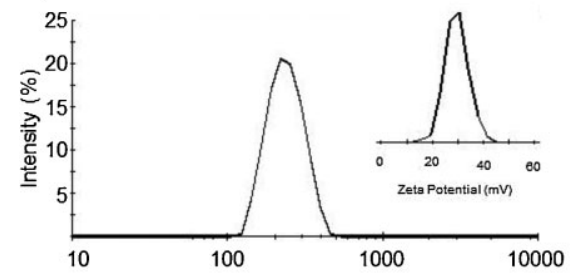

C)

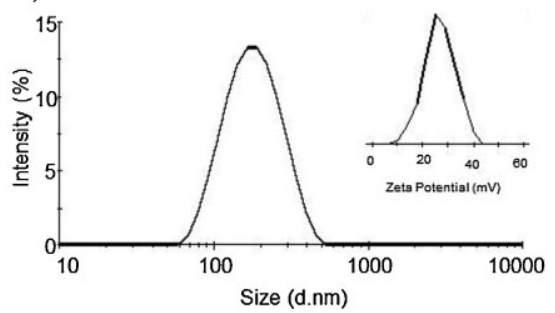

B)
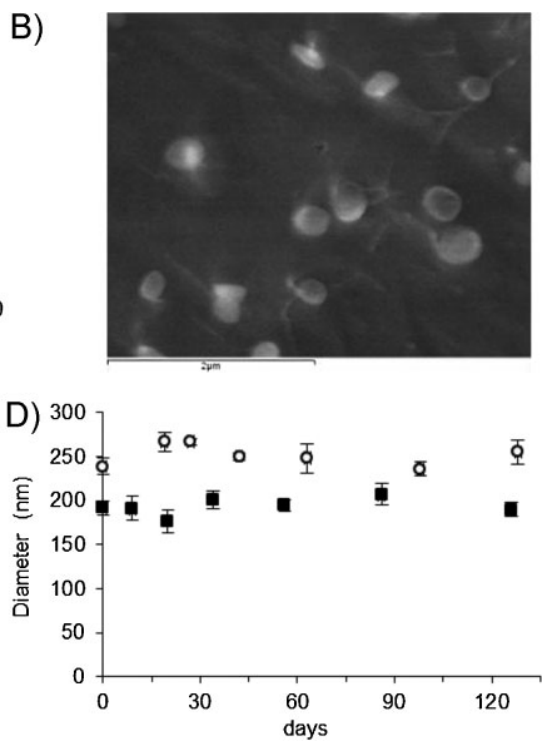

Figure 3. A) Size distribution by intensity, zeta potential and B) Cryo-FESEM micrograph of GC nanogel (scale bar: $2 \mu \mathrm{m}$ );C) size distribution by intensity and zeta potential of GCFA nanogel; D) colloidal stability of nanogels evaluated by average hydrodynamic diameter of GC $(O)$ and GCFA $(\boldsymbol{\square})$ nanogels overtime. Both nanogel samples were prepared in distilled water and stored at $4{ }^{\circ} \mathrm{C}$. The measurements were performed at 

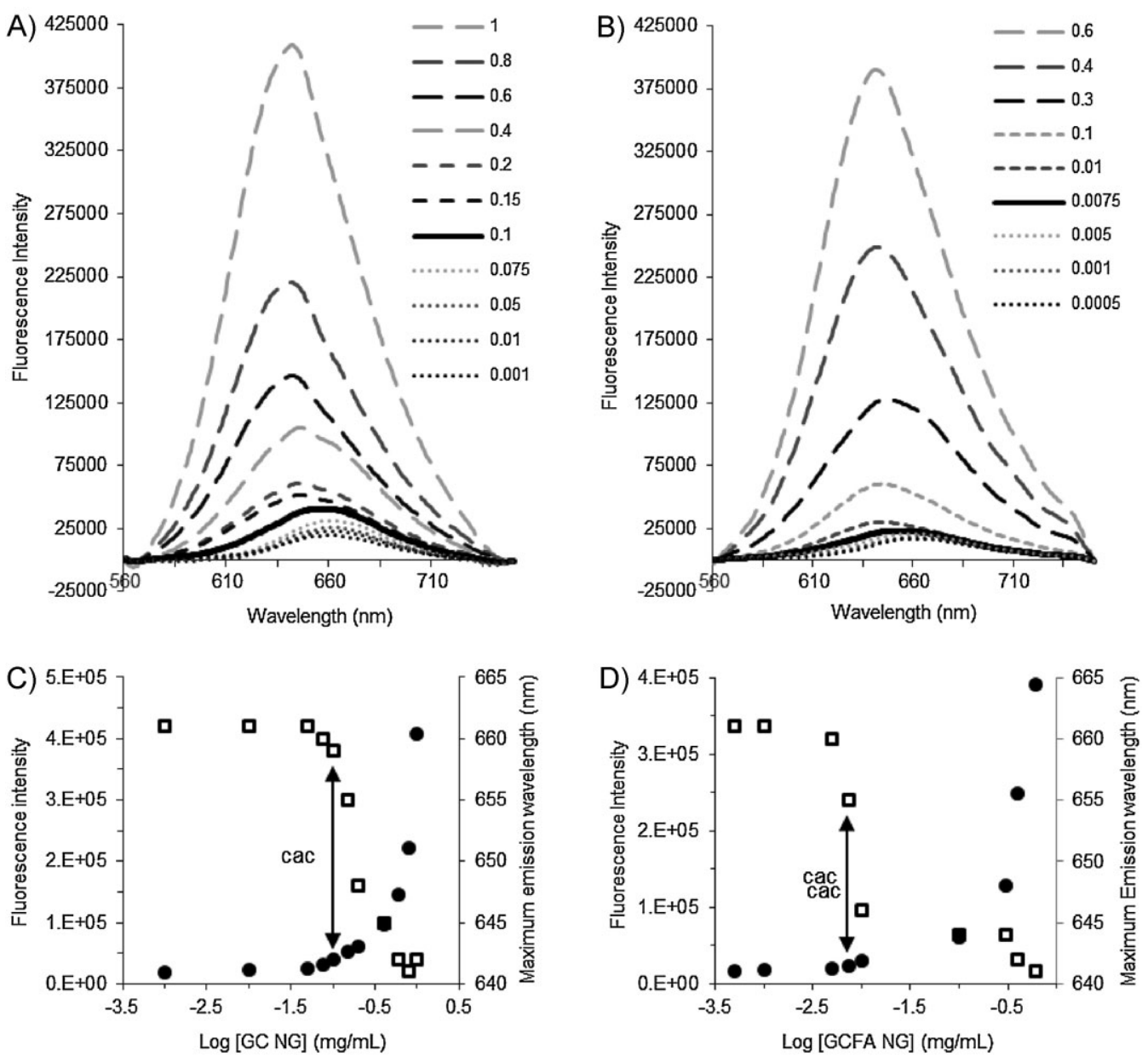

Figure 4. Emission spectra of Nile red $\left(2 \times 10^{-7} \mathrm{M}\right)$ as function of A) GC and B) GCFA nanogel concentration in $\mathrm{mg} / \mathrm{mL}\left(\lambda_{\mathrm{ex}}=550 \mathrm{~nm}\right) ; \mathrm{Plot}$ of fluorescence intensity (O) and maximum emission wavelength ( $\square$ ) of NR versus C) GC or D) GCFA nanogel concentration.

Self-aggregation behavior of GC and GCFA nanogels was studied using Nile Red (NR) as a hydrophobic fluorescent probe, whose absorbance and emission maxima shift to higher wavelengths with increasing polarity of the probe environment. ${ }^{[27,28]}$ The fluorescence emission spectra of $\mathrm{NR}$ as function of the nanogel concentration are shown in Figure 4A and B, respectively. At low concentrations, in aqueous solution, the emission is close to the background intensity. However, the intensity increases abruptly above a certain nanogel concentration, indicating the formation of hydrophobic regions able to dissolve the NR probe. Associated with the increased fluorescence intensity, a shift of the emission maxima towards lower wavelengths was observed with the increase of the nanogel concentration, due to the lower polarity surrounding the probe hydrophobic cores of the nanogels. ${ }^{[29]}$ This transitional concentration is commonly named CAC, the minimal concentration required for the amphiphilic polysaccharide conjugates (Figure 4D) to self-assemble forming a nanogel.
The CAC value of the GC nanogel was $0.1 \mathrm{mg} \mathrm{mL}^{-1}$ (Figure 4C). Values in the same order of magnitude have been reported by ref. ${ }^{[30]}$ for fluorescent chitosan nanoparticles $\left(0.06 \mathrm{mg} \mathrm{mL}^{-1}\right)$ and by ref. ${ }^{[31]}\left(0.123 \mathrm{mg} \mathrm{mL}^{-1}\right)$ for cholesterol modified GC. The modification of the nanogel with PEG, besides conferring increased solubility, also enhances the softness of GC main chain, which facilitates polymer aggregation. ${ }^{[32]}$ Consequently the CAC achieved for the GCFA nanogel was significantly reduced to $0.0075 \mathrm{mg} \mathrm{mL}^{-1}$.

\subsection{Cell Viability}

Chitosan and its derivatives are not significantly toxic, ${ }^{\text {[33] }}$ GC being one of the less toxic derivatives. ${ }^{[34]}$ Further GC modifications could improve or decrease the final cytotoxicity. The effect of the nanogel on cell viability and cell growth was gauged using RAW and HeLa cell lines in a MTT assay. As shown in Figure 5A, the proliferation 


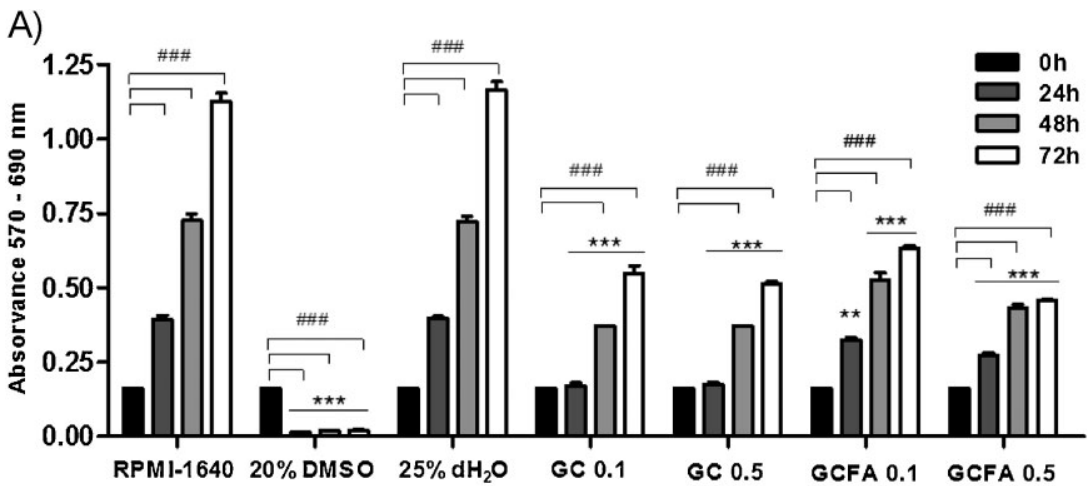

B)

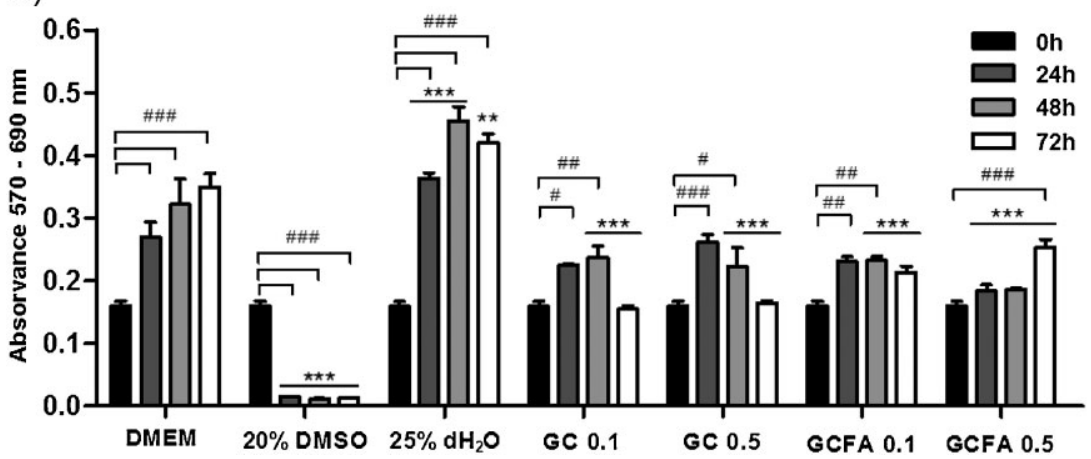

Figure 5. Effect of GC and GCFA nanogels ( 0.1 and $0.5 \mathrm{mg} \mathrm{mL}^{-1}$ ) on viability of A) HeLa and B) RAW cells, measured by MTT assay. Cell culture medium was used as negative control (RPMI-1640 to HeLa cells and DMEM to RAW cell line) and $20 \%$ of DMSO as positive control. Twenty-five percent $\mathrm{dH}_{2} \mathrm{O}$ condition was also studied because each nanogel sample in culture medium containing $25 \%$ of water $\mathrm{v} / \mathrm{v}$. Statistical differences between negative control group (cell culture medium) and remaining samples at each time of incubation are represented as $(*)$ and (\#) means the statistical differences between o $\mathrm{h}$ incubation time and remaining incubation times for each condition. Significance degree (one, two, or three symbols) was chosen according to $p$ values ( $p<0.05, p<0.01$, and $p<0.0001$, respectively).

of HeLa cells was significantly affected in the presence of the nanogels. However, cell growth was still observed. Indeed, the treated cells were able to grow, although with a lower rate than observed for the controls. The RAW cell line (Figure 5B) exhibited an even slower growth rate, but the cell number never decreased below the initial value, suggesting that cell viability is not compromised. Overall, the presence of folate did not affect the cell viability, in agreement with the observation by $\mathrm{Ou}$ et al., ${ }^{[35]}$ who reported that folate moieties did not influence cell cytotoxicity.

\subsection{Cellular Uptake}

\subsubsection{In Vitro Targeting Ability}

Folate receptors are extensively expressed in several kinds of tumor, including cervical cancer. ${ }^{[36]}$ Hence,
HeLa cells were used to assess the targeting ability conferred by the folate moiety grafted on the nanogel surface. Cells treated with the nanogels labeled with a fluorescent probe were observed by confocal microscopy (Figure 6A,B). Cells incubated with nanogel without ligand exhibited a fluorescent signal punctuated on the cell surface and minimal fluorescence on the cytoplasm, as shown in the amplified insert image. Probably, in the absence of targeting ligand and due to the slightly positive surface charge, the nanogel accumulates at the surface of the cellular membrane. In contrast, nanogel bearing folate provided significant internalization, which suggests that the enhancement of GCFA nanogel uptake was due to folate receptor mediated endocytosis (Figure 6C,D).

\subsubsection{BMDM Cellular Uptake}

The interaction with the mononuclear phagocyte system is crucial when a carrier is conceived for systemic application. In order to investigate whether the nanogels are phagocytosed by macrophages, fluorescent nanogels were incubated with BMDM. Figure $7 \mathrm{~A}-\mathrm{C}$ illustrates the cellular uptake of fluorescein isothiocyanate (FITC)-labeled dextrin nanogel (used as a positive control of macrophages uptake, as shown by Gonçalves et al.), ${ }^{[37]}$ NHS-fluorescein labeled GC and GCFA nanogels, respectively. Interestingly, the GC nanogel was poorly internalized by BMDM as compared with dextrin nanoparticles. Sarmento et al. ${ }^{[38]}$ also reported that chitosan coated solid lipid nanoparticles were neglectfully internalized within RAW 264.7 cells, as compared with uncoated solid lipid nanoparticles. As verified by Parveen and Sahoo ${ }^{[11]}$ the PEG content chosen $(\approx 10 \%)$ was determinant on decreasing of macrophage cellular uptake. Indubitably this is a promising result since GC nanogel may thus evade blood clearance and keep on circulation enough time to find the target site. GCFA nanogel was also not internalized by BMDM, hinting that this vehicle is a promising vector for drug and gene delivery. The effectiveness of the GCFA nanogel in escaping macrophage uptake is probably due to the PEG, which avoids opsonization and consequently increases the circulation time in the bloodstream. $^{[11,39]}$ 

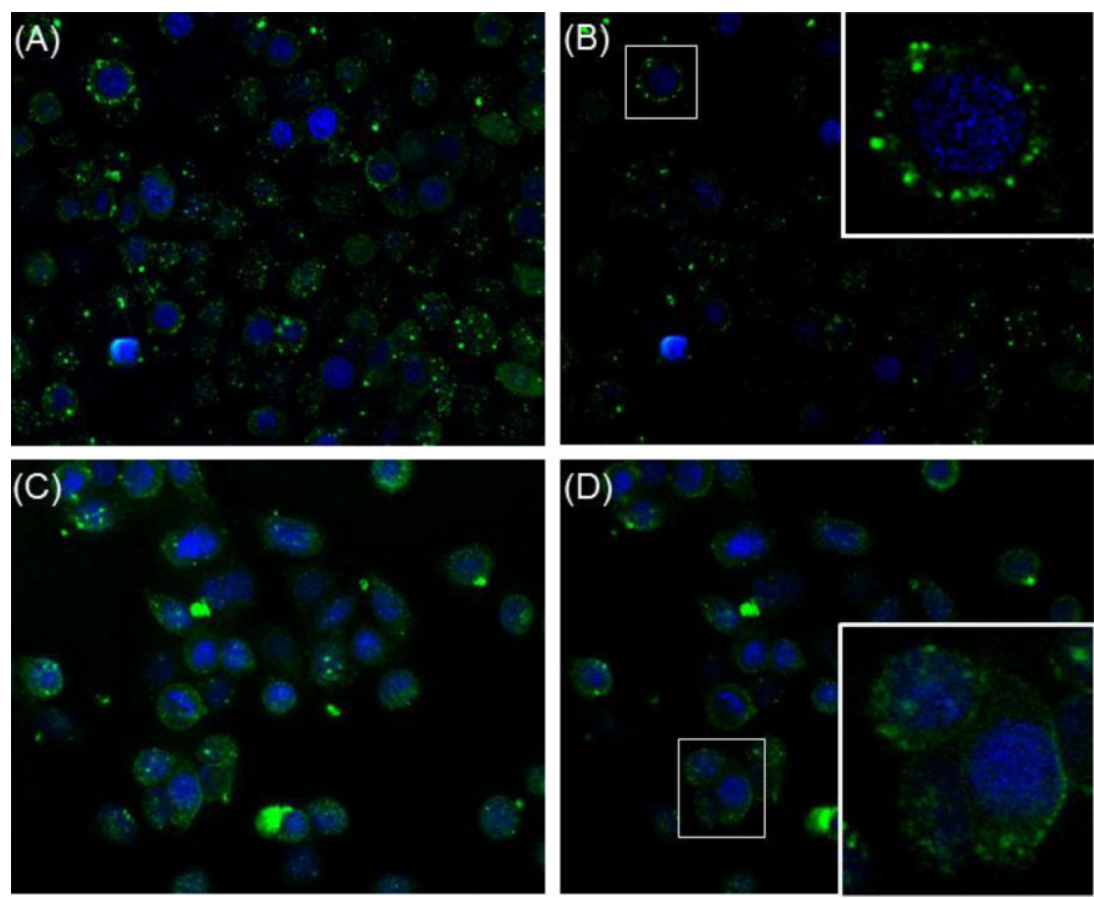

Figure 6. Internalization of nanogels labeled with NHS-fluorescein by HeLa cells with and without folate. A and B) Distribution pattern of non-functionalized nanogel and $C$ and D) nanogel with folate, after sixth hours of incubation. Images on the left correspond to the sum of all captured plans, while images on the right side refer just to the fourth plan, corresponding to an internal section of the cells, such that the observed green fluorescence should correspond to material inside the cells, not surface adsorbed.
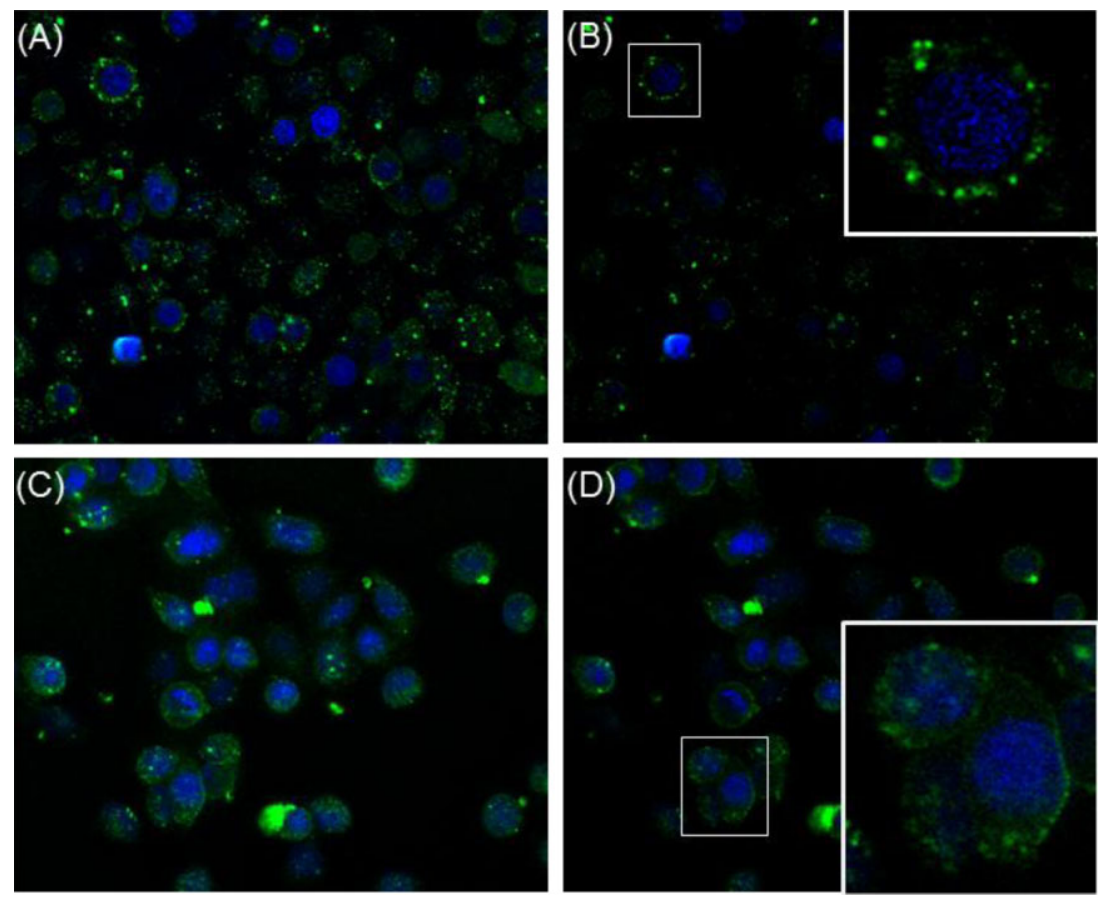

Figure 7. Confocal microscopic images of BMDM treated with fluorescent labeled A) dextrin nanogel, B) GC, and C) GCFA nanogels for $6 \mathrm{~h}$.

\section{5. siRNA-Nanogel Interaction}

The GC nanogel complexes siRNA through electrostatic interactions. As GC possesses amino groups with a $\mathrm{p} K_{\mathrm{a}}$ close to 6.5 , below this $\mathrm{pH}$ the amino groups are protonated. $^{[40,41]}$ Accordingly, in order to induce a stronger interaction between negatively charged phosphate groups from siRNA and positively charged amino groups from GC, we used a nanogel solution in $0.2 \mathrm{M}$ sodium acetate buffer $\mathrm{pH}$ 4.5. A gel retardation assay was used to evaluate the nanogel-siRNA interaction. Figure 8 shows the gelretardation results obtained for different amine $(\mathrm{N}) /$ phosphate $(\mathrm{P})$ ratios. The use of a N/P molar ratio of 10 resulted in a delayed migration of the siRNA, as compared to naked siRNA. However, the electrophoretic mobility of siRNA was retarded more effectively with increasing $\mathrm{N} / \mathrm{P}$ ratio and complete retardation of siRNA migration on agarose matrix was observed for the higher N/P ratio. The retention of siRNA in the loading well suggests that, at this molar ratio, a tight and stable interaction between nanogel and siRNA occurs.

\section{Conclusion}

A self-assembled nanogel made of amphiphilic GC was successfully developed. Decoration with folate moiety conferred the nanogel the ability to improve the interaction with folatereceptor expressing cells, supporting its internalization through receptor-mediated endocytosis. The nanogels were not cytotoxic for the tested cell lines, although growth inhibition was observed to some extent. GC nanogels showed to be attractive for systemic administration due to their ability to escape from macrophages and consequently elongate lifetime in circulation until achieve the target site. GC nanogel proved to be a promising gene carrier, but, besides complexing siRNA efficiently, could also load low-molecular-weight hydrophobic drugs into the hydrophobic core. 

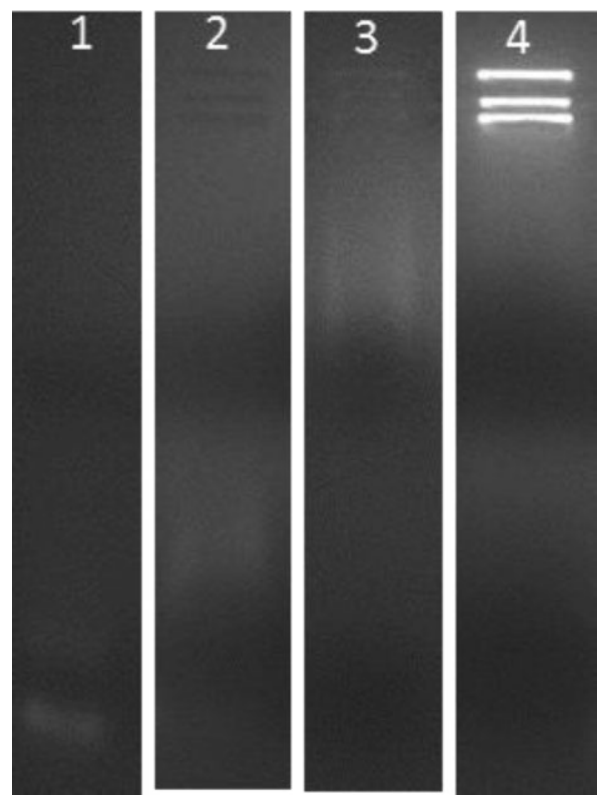

Figure 8. Gel retardation assay of GC nanogel/siRNA complex. Lane 1 is a 21 bp siRNA unknown sequence; lanes $2-4$ are GC/siRNA formulation with N/P molar ratio of 10, 50, and 100, respectively.

Acknowledgements: Paula Pereira thanks FCT, the Ph.D. grant ref SFRH/BD/64977/2009.

Received: February 28, 2013; Revised: May 24, 2013; Published online: August 28, 2013; DOI: 10.1002/mabi.201300123

Keywords: cellular uptake and siRNA delivery; cytotoxicity; glycol chitosan nanogel

[1] S. Mao, W. Sun, T. Kissel, Adv. Drug Delivery Rev. 2010, 62, 12.

[2] M. Garcia-Fuentes, M. J. Alonso, J. Controlled Release 2012, 161, 496.

[3] P. Holzerny, B. Ajdini, W. Heusermann, K. Bruno, M. Schuleit, L. Meinel, M. Keller, J. Controlled Release 2012, 157, 297.

[4] R. Riva, H. Ragelle, A. des Rieux, N. Duhem, C. Jérôme, V. Préat, Chitosan and Chitosan Derivatives in Drug Delivery and Tissue Engineering Chitosan, Springer, Berlin, Heidelberg 2011, p. 19.

[5] T. W. Wong, Recent Pat. Drug Delivery Formul. 2009, 3, 8.

[6] J. H. Na, H. Koo, S. Lee, K. H. Min, K. Park, H. Yoo, S. H. Lee, J. H. Park, I. C. Kwon, S. Y. Jeong, K. Kim, Biomaterials 2011, 32, 5252.

[7] M. S. Huh, S. Y. Lee, S. Park, S. Lee, H. Chung, Y. Choi, Y. K. Oh J. H. Park, S. Y. Jeong, K. Choi, K. Kim, I. C. Kwon, J. Controlled Release 2010, 144, 134

[8] S. Xu, M. Dong, X. Liu, K. A. Howard, J. Kjems, F. Besenbacher, Biophys. J. 2007, 93, 952.

[9] J. You, X. Li, F. de Cui, Y. Z. Du, H. Yuan, F. O. Hu, Nanotechnology 2008, 19, 045102

[10] P. Chan, M. Kurisawa, J. E. Chung, Y. Y. Yang, Biomaterials $2007,28,540$
[11] S. Parveen, S. K. Sahoo, Eur. J. Pharmacol. 2011, 670, 372.

[12] S. Kwon, J. H. Park, H. Chung, I. C. Kwon, S. Y. Jeong, I.-S. Kim, Langmuir 2003, 19, 10188.

[13] J.-H. Kim, Y.-S. Kim, S. Kim, J. H. Park, K. Kim, K. Choi, H. Chung, S. Y. Jeong, R.-W. Park, I.-S. Kim, I. C. Kwon, J. Controlled Release 2006, 111, 228.

[14] Y. Zheng, X. Song, M. Darby, Y. Liang, L. He, Z. Cai, O. Chen, Y. Bi, X. Yang, J. Xu, Y. Li, Y. Sun, R. J. Lee, S. Hou, J. Biotechnol. 2010, 145, 47

[15] V. Carvalho, P. Castanheira, P. Madureira, S. A. Ferreira, C. Costa, J. P. Teixeira, C. Faro, M. Vilanova, M. Gama, Biotechnol. Bioeng. 2011, 108, 1977.

[16] F. Cerca, F. Andrade, A. Franca, E. B. Andrade, A. Ribeiro, A. A. Almeida, N. Cerca, G. Pier, J. Azeredo, M. Vilanova, J. Med. Microbiol. 2011, 60, 1717.

[17] T. Mosmann, J. Immunol. Methods 1983, 65, 55.

[18] I. F. Uchegbu, A. G. ScháTzlein, L. Tetley, A. I. Gray, J. Sludden, S. Siddique, E. Mosha, J. Pharm. Pharmacol. 1998, 50, 453.

[19] C. Dufes, J. M. Muller, W. Couet, J. C. Olivier, I. F. Uchegbu, A. G. Schatzlein, Pharm. Res. 2004, 21, 101.

[20] Y. W. Cho, S. A. Park, T. H. Han, D. H. Son, J. S. Park, S. J. Oh, D. H. Moon, K. J. Cho, C. H. Ahn, Y. Byun, I. S. Kim, I. C. Kwon, S. Y. Kim, Biomaterials 2007, 28, 1236.

[21] K. Park, J.-H. Kim, Y. S. Nam, S. Lee, H. Y. Nam, K. Kim, J. H. Park, I.-S. Kim, K. Choi, S. Y. Kim, I. C. Kwon, J. Controlled Release 2007, 122, 305.

[22] D. K. Knight, S. N. Shapka, B. G. Amsden, J. Biomed. Mater. Res. A 2007, 83, 787.

[23] M. Lavertu, Z. Xia, A. N. Serreqi, M. Berrada, A. Rodrigues, D. Wang, M. D. Buschmann, A. Gupta, J. Pharm. Biomed. Anal. 2003, 32, 1149.

[24] A. Hirai, H. Odani, A. Nakajima, Polym. Bull. 1991, 26, 87.

[25] Y. l. Tan, C. G. Liu, J. Mater. Sci.: Mater. Med. 2011, 22, 1213.

[26] K. Krauel, L. Girvan, S. Hook, T. Rades, Micron 2007, 38, 796.

[27] G. Nizri, S. Magdassi, J. Colloid Interface Sci. 2005, 291, 169.

[28] M. M. G. Krishna, J. Phys. Chem. A 1999, 103, 3589.

[29] P. J. G. Coutinho, E. M. S. Castanheira, M. C. Rei, M. E. C. D. R. Oliveira, J. Phys. Chem. B 2002, 106, 12841.

[30] W. Cui, X. Lu, K. Cui, J. Wu, Y. Wei, O. Lu, Langmuir 2011, 27, 8384.

[31] A. Sahu, U. Bora, N. Kasoju, P. Goswami, Acta Biomater. 2008, 4, 1752.

[32] X. Yang, O. Zhang, Y. Wang, H. Chen, H. Zhang, F. Gao, L. Liu, Colloids Surf. B Biointerfaces 2008, 61, 125.

[33] T. Kean, M. Thanou, Adv. Drug Delivery Rev. 2010, 62, 3.

[34] B. Carreño-Gómez, R. Duncan, Int. J. Pharm. 1997, 148, 231.

[35] D. Ou, H. Lin, N. Zhang, J. Xue, C. Zhang, Carbohydr. Polym. 2012, 92, 545

[36] V. B. Morris, C. P. Sharma, J. Colloid Interface Sci. 2010, 348, 360.

[37] C. Goncalves, E. Torrado, T. Martins, P. Pereira, J. Pedrosa, M. Gama, Colloids Surf. B Biointerfaces 2010, 75, 483.

[38] B. Sarmento, D. Mazzaglia, M. C. Bonferoni, A. P. Neto, M. do Céu Monteiro, V. Seabra, Carbohydr. Polym. 2011, 84, 919.

[39] F. O. Hu, P. Meng, Y. O. Dai, Y. Z. Du, J. You, X. H. Wei, H. Yuan, Eur. J. Pharm. Biopharm. 2008, 70, 749.

[40] G. Bajaj, W. G. Van Alstine, Y. Yeo, PLoS ONE 2012, 7, 30899.

[41] J. Malmo, H. Sorgard, K. M. Varum, S. P. Strand, J. Controlled Release 2012, 158, 261. 